\title{
Neural Network Control-Based Drive Design of Servomotor and Its Application to Automatic Guided Vehicle
}

\author{
Ming-Shyan Wang, ${ }^{1}$ Seng-Chi Chen, ${ }^{1}$ Po-Hsiang Chuang, \\ Shih-Yu Wu, ${ }^{1}$ and Fu-Shung Hsu ${ }^{2}$ \\ ${ }^{1}$ Department of Electrical Engineering, Southern Taiwan University of Science and Technology, 1 Nan-Tai Street, \\ Yung Kang District, Tainan City 710, Taiwan \\ ${ }^{2}$ Eternity Electronic Industrial Company, Tainan City 717, Taiwan
}

Correspondence should be addressed to Ming-Shyan Wang; mswang@mail.stust.edu.tw

Received 14 September 2014; Accepted 2 December 2014

Academic Editor: Mo Li

Copyright (C) 2015 Ming-Shyan Wang et al. This is an open access article distributed under the Creative Commons Attribution License, which permits unrestricted use, distribution, and reproduction in any medium, provided the original work is properly cited.

An automatic guided vehicle (AGV) is extensively used for productions in a flexible manufacture system with high efficiency and high flexibility. A servomotor-based AGV is designed and implemented in this paper. In order to steer the AGV to go along a predefined path with corner or arc, the conventional proportional-integral-derivative (PID) control is used in the system. However, it is difficult to tune PID gains at various conditions. As a result, the neural network (NN) control is considered to assist the PID control for gain tuning. The experimental results are first provided to verify the correctness of the neural network plus PID control for $400 \mathrm{~W}$-motor control system. Secondly, the AGV includes two sets of the designed motor systems and CAN BUS transmission so that it can move along the straight line and curve paths shown in the taped videos.

\section{Introduction}

There is no doubt about the importance and popularity of an automatic guided vehicle (AGV) in a flexible manufacture system and an automatic warehousing system. There are many research topics on AGV, such as an inductive power transfer (IPT) system [1] that transfers power from one circuit to another through electromagnetic induction without any physical contact, wireless position tracking by radio frequency identification (RFID) method [2] that is costeffective, precise docking maneuvers to pick up or deliver the transport load by control techniques-fuzzy, vector pursuit, and flatness-based control to satisfy the robustness requirements [3], and landmark-based localization techniques to receive considerable attention in providing accurate location estimates [4], and so forth. The AGV based on an electric actuation system will provide a very important advantage during carriage transportation, free of air pollution.

Based on the back electromotive forces (EMFs), there are two types of servomotors, the permanent magnet synchronous motor (PMSM) with sinusoidal waveform, and the brushless DC motor (BLDCM) with trapezoidal one. They are more widely applied than before in the servocontrol-systems. Comparing with the traditional DC motor and induction motor, the BLDCM provides the merits of no brushes, low consumption, low volume, better stability, and larger torque. Furthermore, BLDCM uses the Hall-effect sensors as position sensors for feedback control rather than the expensive encoders used by PMSM. As a result, BLDCMs are popular in industrial automation systems, such as modern electric vehicles [5], automotive returnless fuel pumps [6], appliances, computers, automatic office machines, manufactory robots for automation, drives of many electronics and minuteness machines.In this paper, two BLDCMs are adopted in the designed AGV prototype.

However, due to using low-cost Hall-effect sensors, BLDCMs are driven by using six-step commutation strategy, which nevertheless accompanies larger torque ripple and less smoothing rotation. On speed computing, the simplest and most popular one is $\mathrm{M}$ method that counts the number of the Hall-effect sensors' outputs in a fixed speed sampling period to estimate the averaged speed. T method measures 


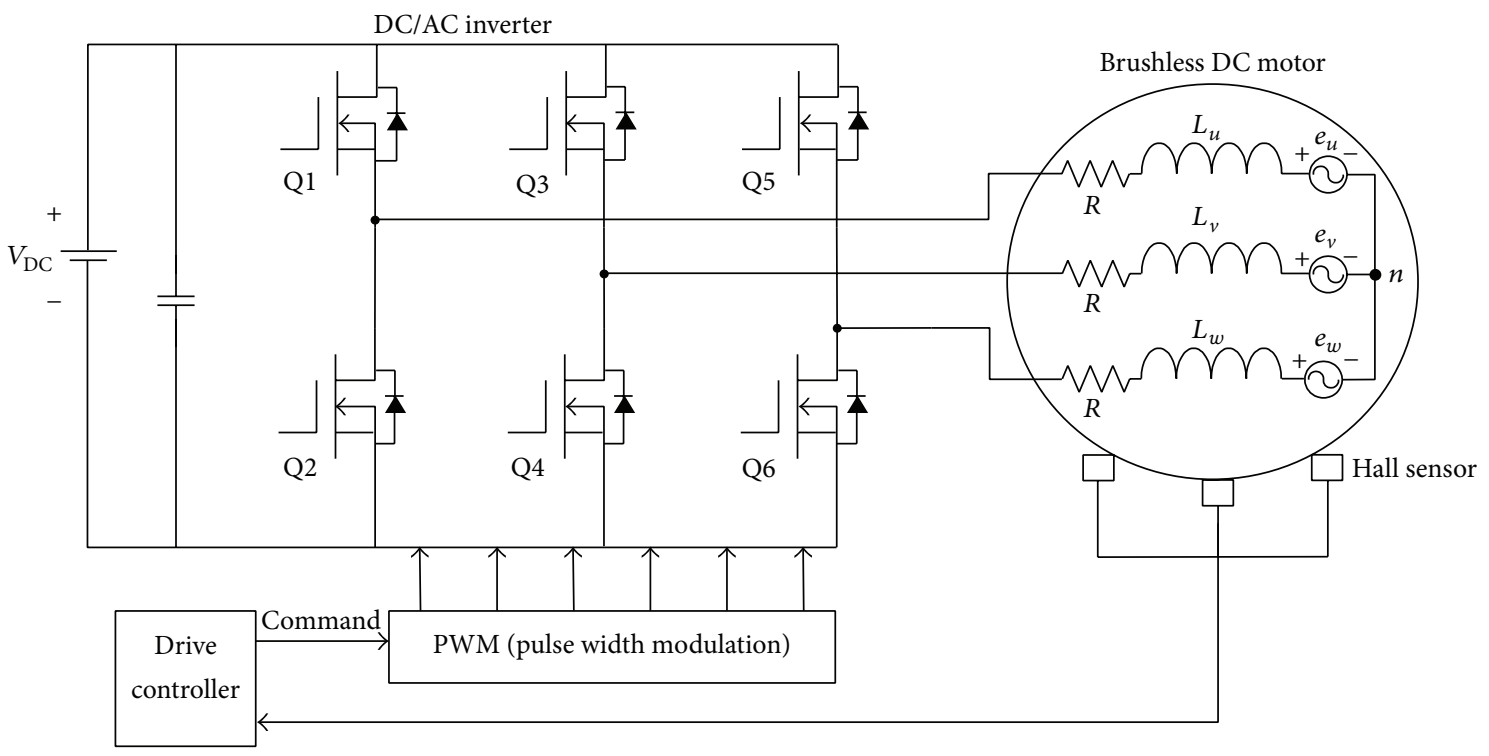

FIGURE 1: Block diagram of the BLDC motor control system.

the velocity by counting high-frequency clock pulses in one Hall-effect sensor's output interval time [7]. M method is only suitable at very high speed. T method is usable at medium speed area. These problems have motivated research in the area of motor design [5] and sinusoidal exciting algorithm [8]. In spite of sinusoidal excitation, we will adopt the neural network control to compensate the traditional proportionalintegral-derivative (PID) gains for speed adjustment such that we can regulate the speed around the predefined path with corner and/or arc.

Recently, artificial neural networks (ANNs) have attracted much attention to their possible use in a wide range of engineering applications like power electronics and motor drives [9-14]. The use of ANNs is motivated by their useful features such as parallel distributed architecture, ability to identify nonlinear system dynamics, and the ability to learn, generalize, and adapt. All of these features justify the use of ANNs for motor drive applications.

The motor speed will be regulated through the pulse-width modulation (PWM) which is generated by dsPIC33EP64MC506 [15], a product from Microchip Technology Inc. This microcontroller includes the enhanced controller area network (ECAN) bus for communication. CAN was developed by Bosch to overcome the limitations of conventional control device linkage and vehicle optimization for future developments. It has also been standardized internationally (ISO 11898) and has been "cast in silicon" by several semiconductor manufacturers. Two sets of motors and drives with a central control unit which handles all of the commands of motion constitute the designed AGV prototype. The proposed AGV system can stably go along the straight line and across the corner with the appropriate speed.

This paper presents a neural network based approach to the speed control of the BLDC motor. The basic premise of the method is that an ANN provides a very efficient mapping structure for the nonlinear BLDC motor. By measuring the speed and excitation by PID control to apply them as inputs to the NN, exciting signal is adjusted, thereby facilitating the elimination of the speed variation. The paper is organized as follows for further discussion. Section 2 introduces system description including BLDCM modeling and speed control by PID and ANN. Section 3 consists of experimental results. Finally, conclusions are given in Section 4 .

\section{Servosystem Design}

There are three parts for the proposed servo-control-system design, PMSM modeling, sliding-mode observer (SMO) with LMS approach, and PI speed control compensated by neural networks.

2.1. BLDCM Modeling. The voltage equation and mechanic equation of a BLDCM are given as follows [5-7]:

$$
\begin{aligned}
& {\left[\begin{array}{c}
v_{u} \\
v_{v} \\
v_{w}
\end{array}\right]=} {\left[\begin{array}{lll}
R & 0 & 0 \\
0 & R & 0 \\
0 & 0 & R
\end{array}\right]\left[\begin{array}{c}
i_{u} \\
i_{v} \\
i_{w}
\end{array}\right] } \\
&+\frac{d}{d t}\left[\begin{array}{ccc}
L-M & 0 & 0 \\
0 & L-M & 0 \\
0 & 0 & L-M
\end{array}\right]\left[\begin{array}{l}
i_{u} \\
i_{v} \\
i_{w}
\end{array}\right]+\left[\begin{array}{l}
e_{u} \\
e_{v} \\
e_{w}
\end{array}\right], \\
& \frac{d \omega_{r}}{d t}=\frac{1}{J}\left(T-T_{L}-B \omega_{r}\right)
\end{aligned}
$$

where $v_{u}, v_{v}$, and $v_{w}$ are voltages of phases of $u, v$, and $w ; i_{u}$, $i_{v}$, and $i_{w}$ are currents of phases of $u, v$, and $w ; e_{u}, e_{v}$, and $e_{w}$ are back electromagnetic forces of phases of $u, v$, and $w ; T_{L}$ and $T$ are load torque and the output torque of the motor; $\omega_{r}$ is the motor speed; and $R, L$, and $M$ are the resistance, phase inductance and mutual inductance; and $J$ and $B$ are the inertia of momentum and viscous coefficient. Figure 1 shows 


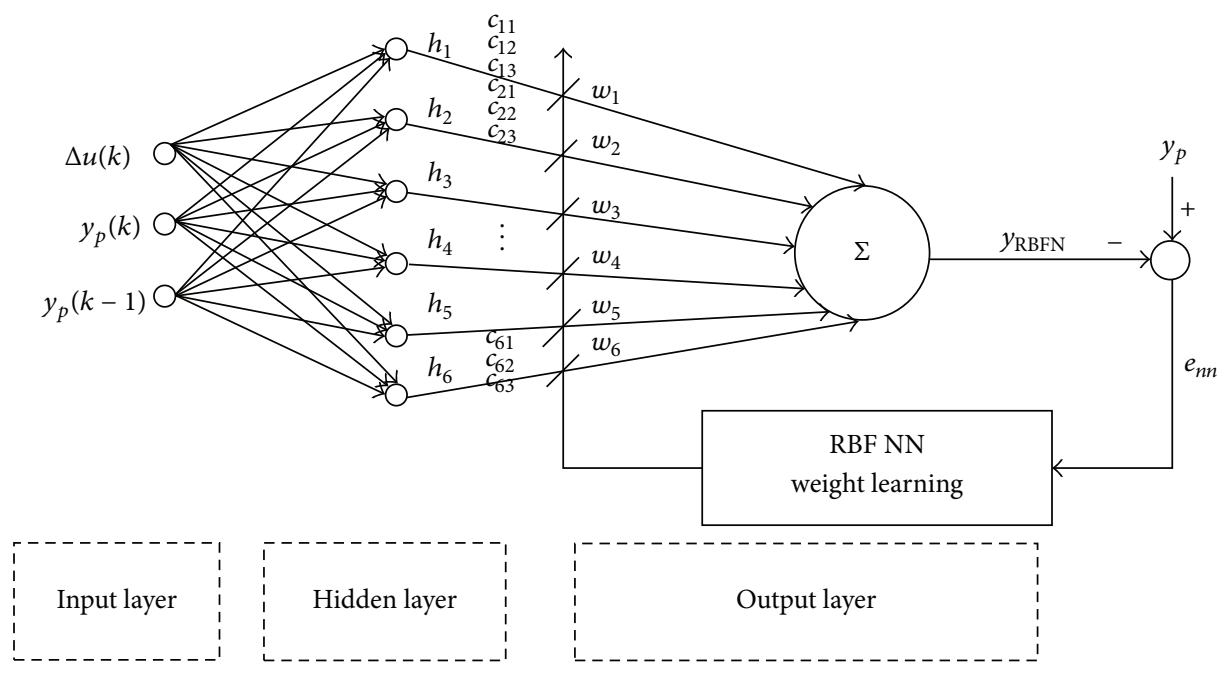

FIgURE 2: Architecture of the RBFN.

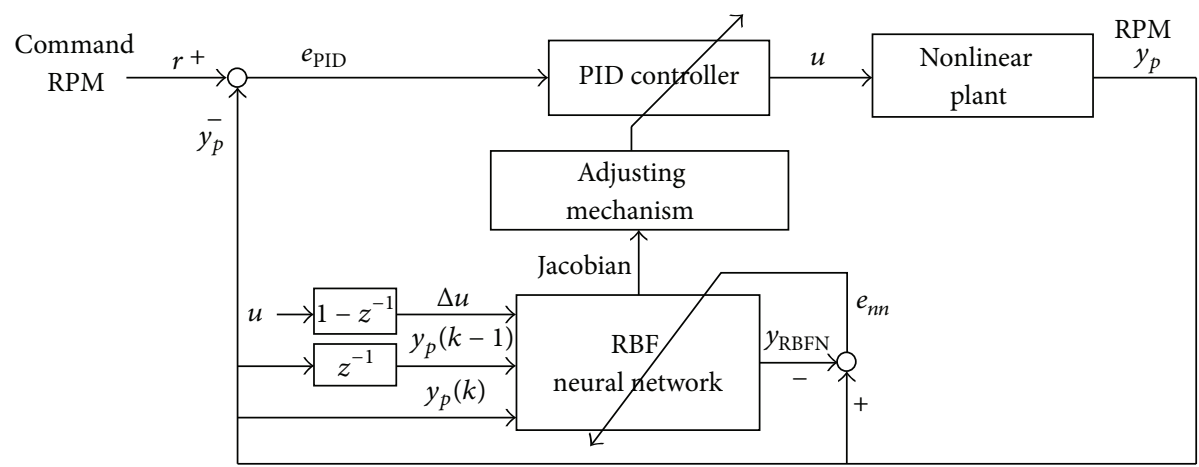

FIGURE 3: Block diagram with RBFN.

the general block diagram of control system for BLDCM with an inverter which consists of six power MOSFETs as switching devices for commutation. Three Hall-effect sensors are also shown.

2.2. Speed Control Design. The PID control is first considered in the system,

$$
G_{s}(s)=K_{p}+\frac{K_{i}}{s}+K_{d} s
$$

where $K_{p}, K_{i}$, and $K_{d}$ are the proportional gain, integral gain, and derivative gain, respectively. PID control is widely used in the industrial applications. However, it cannot cope with the load variation or parameter variation well. In the paper, the radial basis function network (RBFN) is utilized to compensate the PID control quantities.

Artificial neural networks are similar to biological NNs in the sense that they are based on the same principle of operation of highly parallel structure and acquiring knowledge through a learning process [16]. The building blocks of an ANN are simple computational nodes, called neurons. They are connected into a network structure by weighted connections, much like the synaptic connections in the human brain. Although the components of an $\mathrm{NN}$ are simple and few, the structure and type of these networks vary greatly, determined by the ever increasing interest in this research field. RBFN always includes three layers: the input layer, the hidden layer, and the output layer as shown in Figure 2. The input vector is

$$
x=\left[\begin{array}{lll}
\Delta u(k) & y_{p}(k) & y_{p}(k-1)
\end{array}\right]^{T},
$$

where $y_{p}(k)$ is the motor speed at the instant of $k$ and $\Delta u(k)$ is the difference between the actuating signals at the instants of $k$ and $k-1$. The activation function is

$$
h_{j}=\exp \left(-\frac{\left\|x-c_{j}\right\|^{2}}{2 b_{j}^{2}}\right),
$$

where $c_{j}=\left[\begin{array}{llll}c_{j 1} & c_{j 2} & \cdots & c_{j n}\end{array}\right]^{T}$ and $b_{j}$ are the center of the $j$ th neuron at the hidden layer and bias, respectively. And the output of the RBFN is given as

$$
y_{\mathrm{RBFN}}=w_{1} h_{1}+w_{2} h_{2}+\cdots+w_{m} h_{m}=\sum_{j=1}^{m} w_{j} h_{j},
$$

where $w_{j}$ is the weighting factor of the $j$ th neuron at the hidden layer. The experimental block diagram of the BLDCM control system with RBFN is shown in Figure 3. 


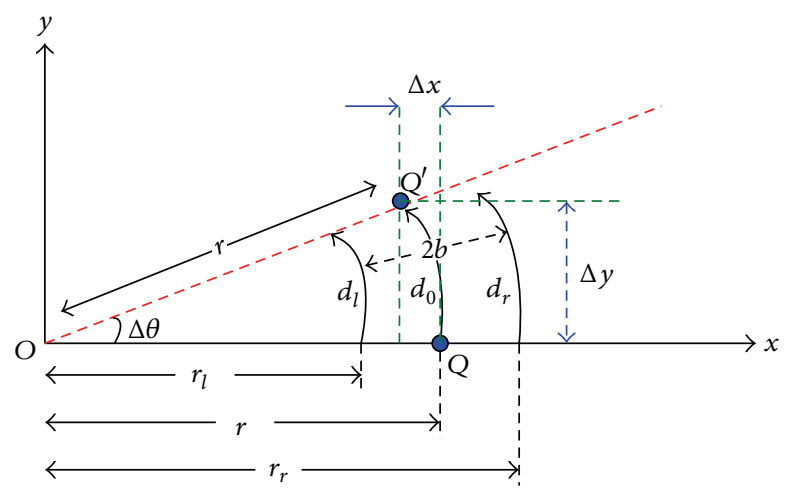

FIGURE 4: Rotating motion.

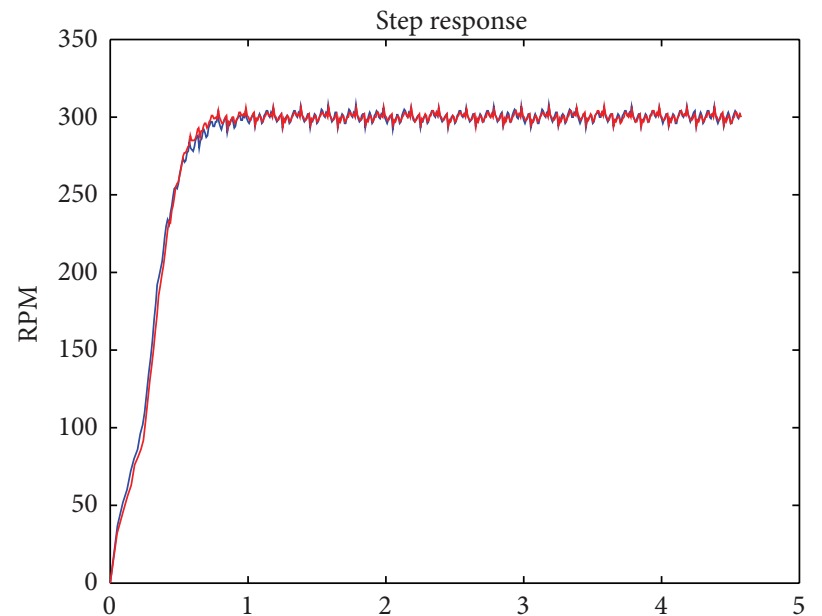

(s)

FIGURE 5: Step responses of $300 \mathrm{rpm}$ by PID control without (blue curve) and with loading (red one).

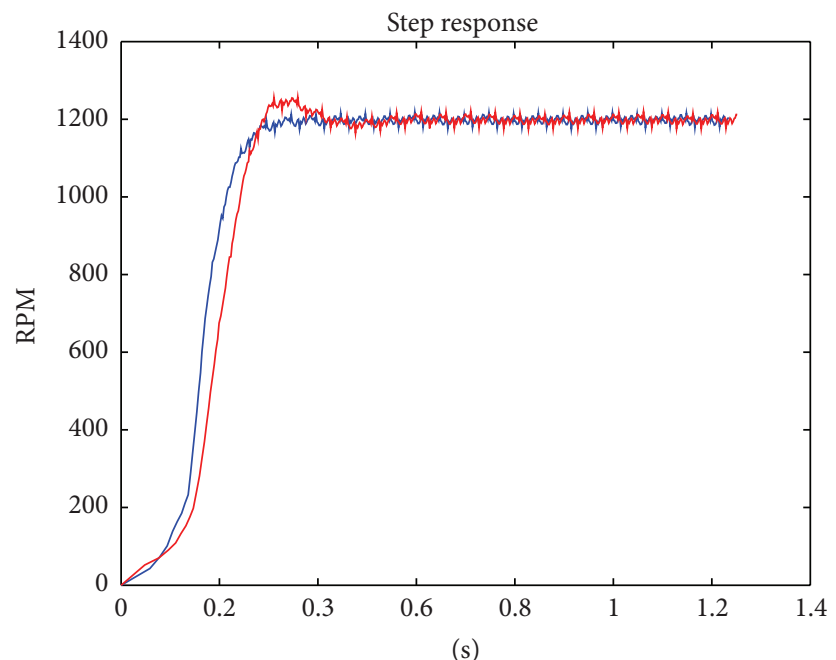

FIGURE 6: Step responses of $1200 \mathrm{rpm}$ by PID control without (blue curve) and with loading (red one). 


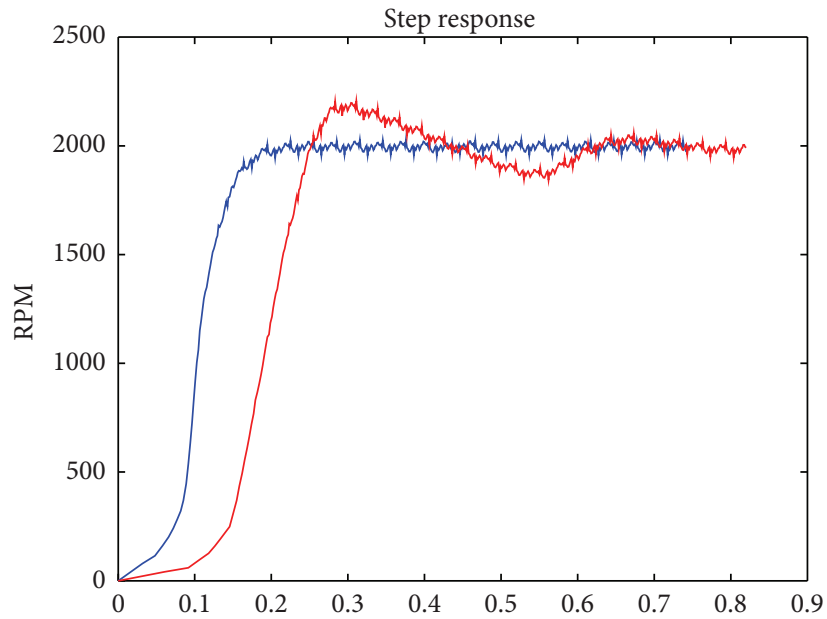

(s)

FIGURE 7: Step responses of $2000 \mathrm{rpm}$ by PID control without (blue curve) and with loading (red one).

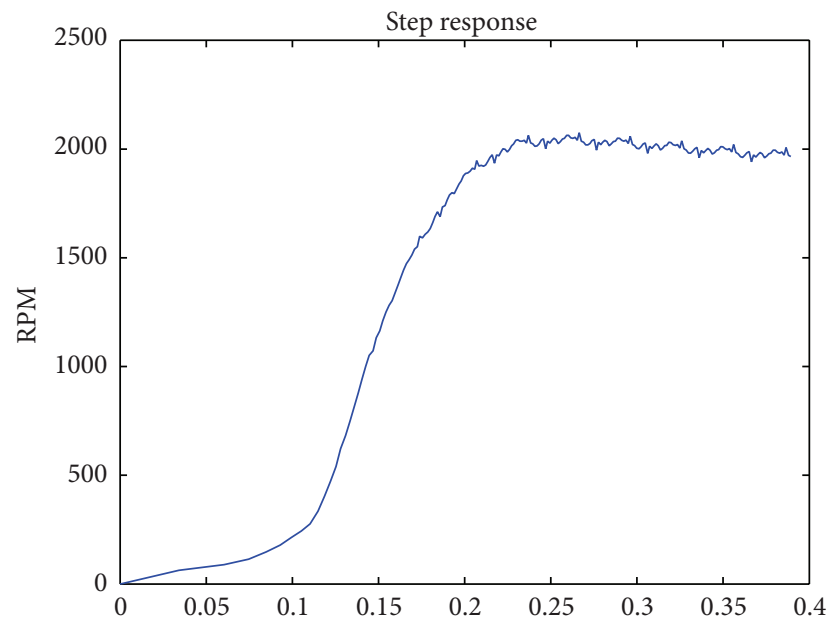

(s)

FIGURE 8: Step response of $2000 \mathrm{rpm}$ by PID control compensated by RBFN with loading.
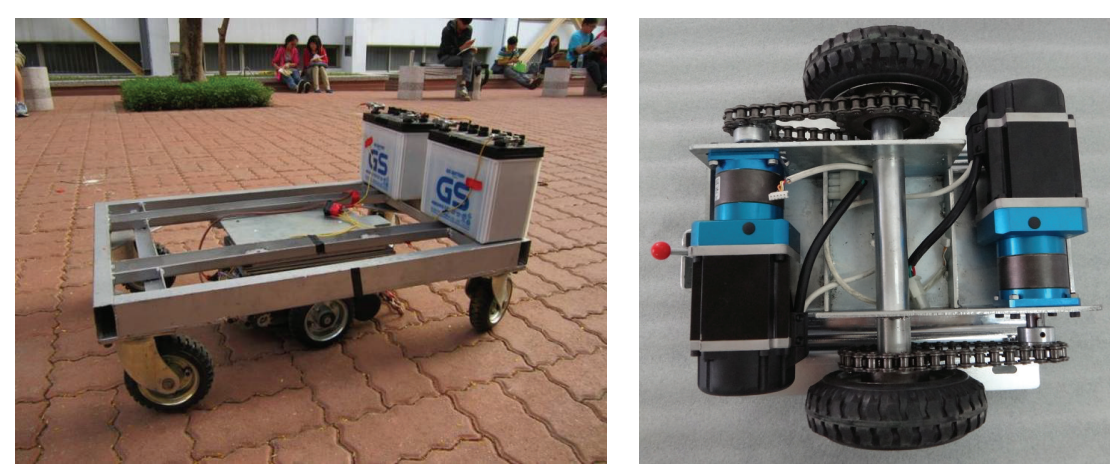

FIGURE 9: The pictures of the AGV prototype. 


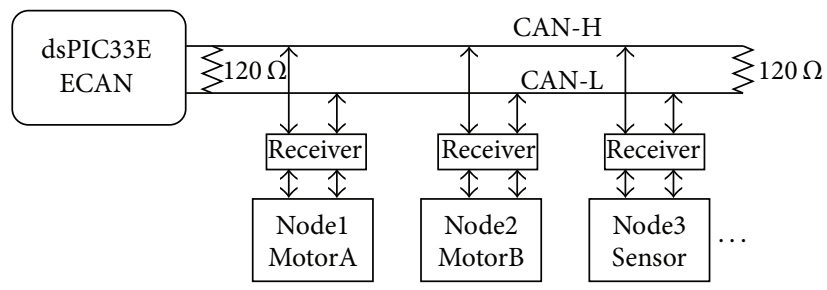

FIGURE 10: The architecture of CAN bus.

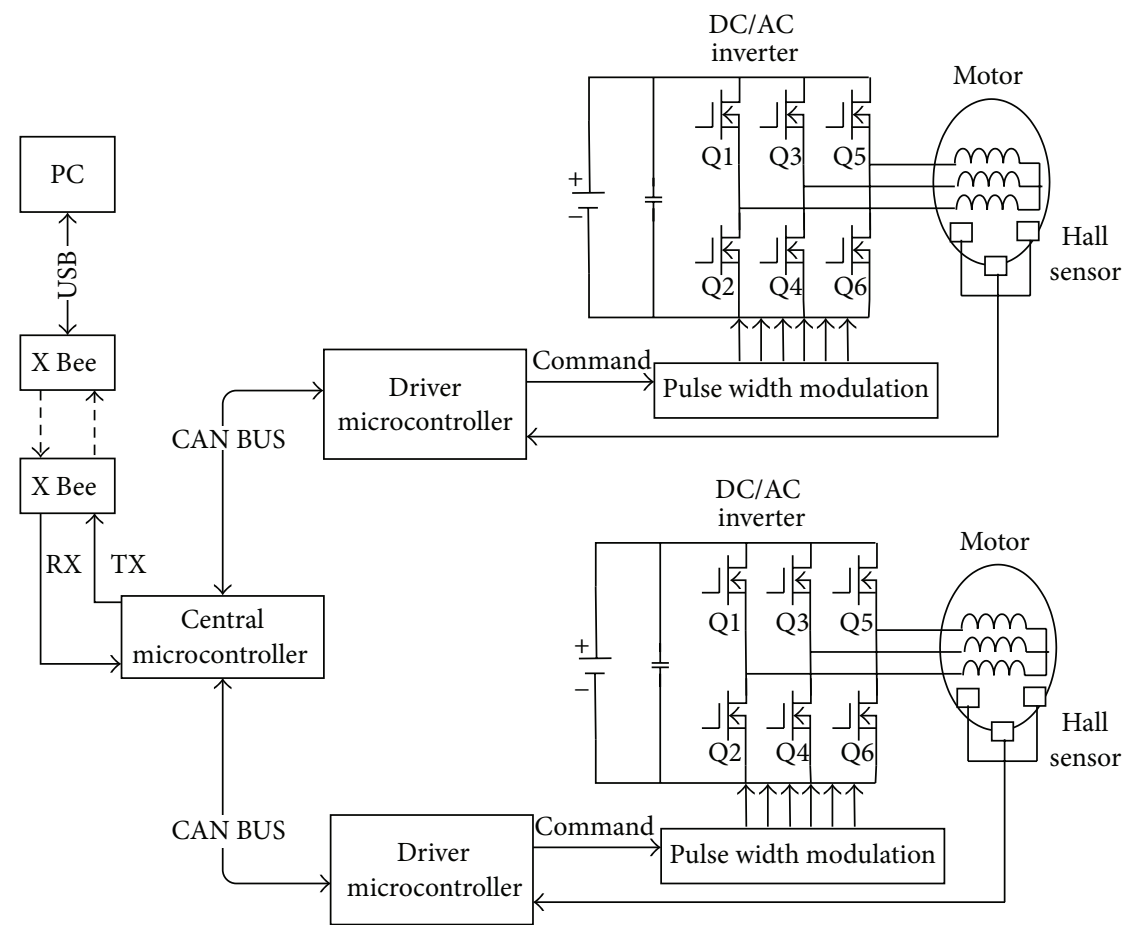

FIGURE 11: The block diagram of the AGV prototype.

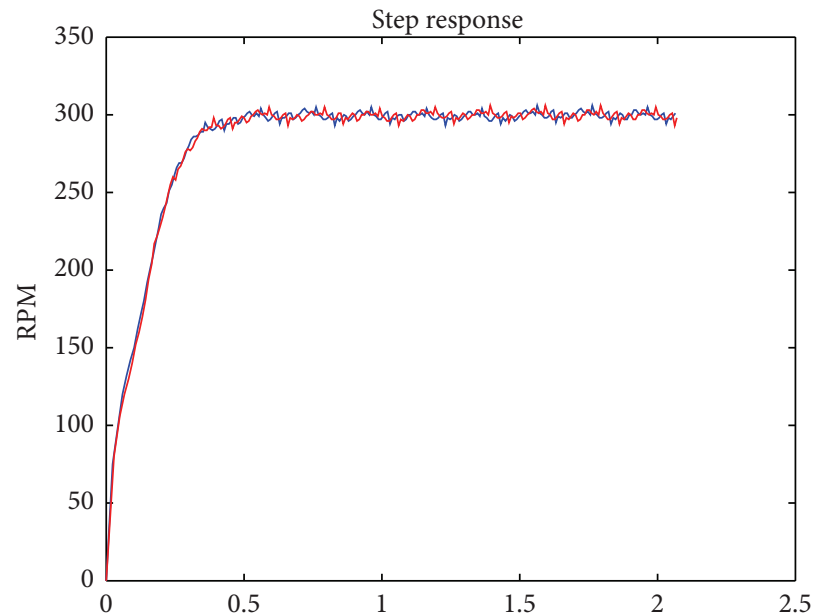

(s)

FIGURE 12: The simultaneous speed responses of $300 \mathrm{rpm}$ for left (red) and right (blue) wheels. 


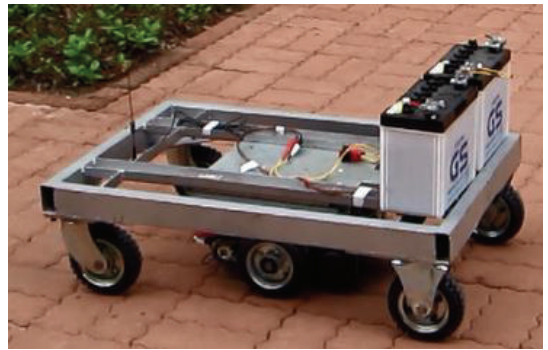

(a)

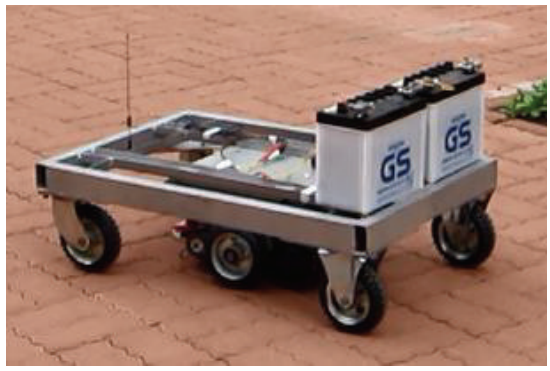

(d)

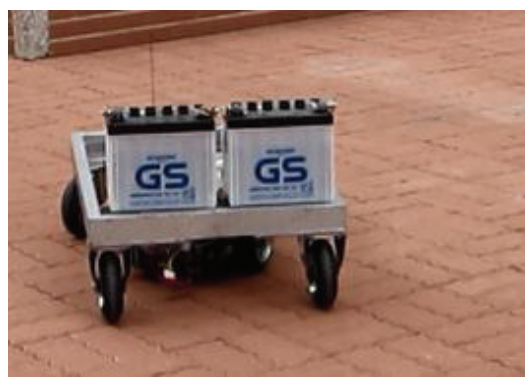

(g)

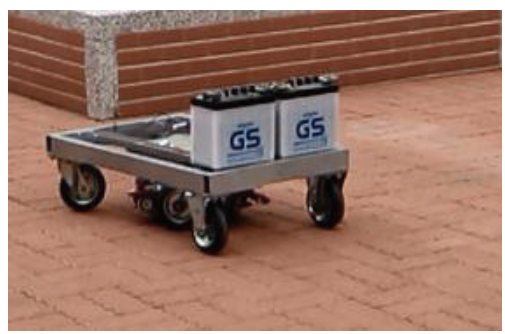

(j)

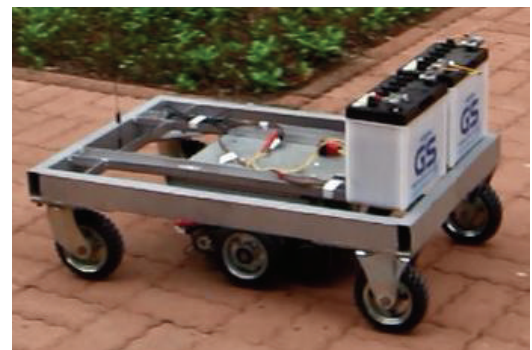

(b)

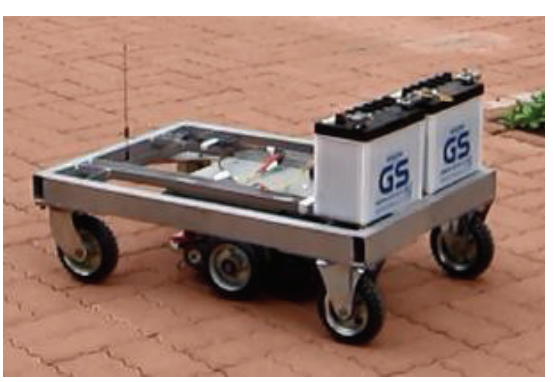

(e)

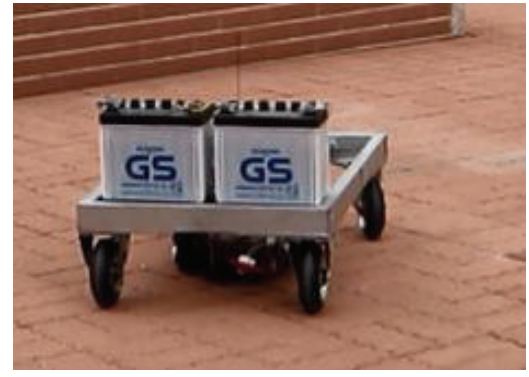

(h)

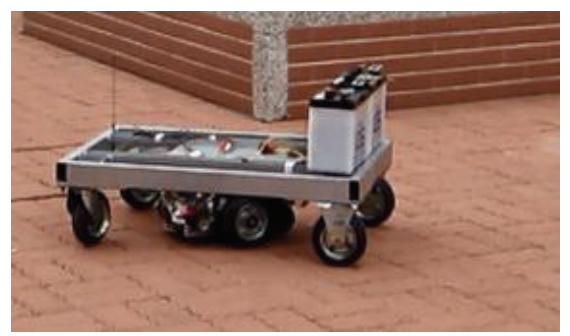

(k)

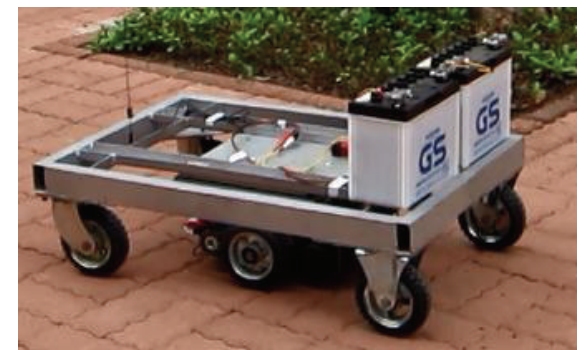

(c)

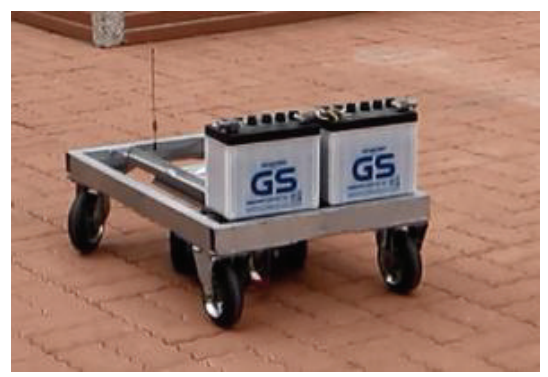

(f)

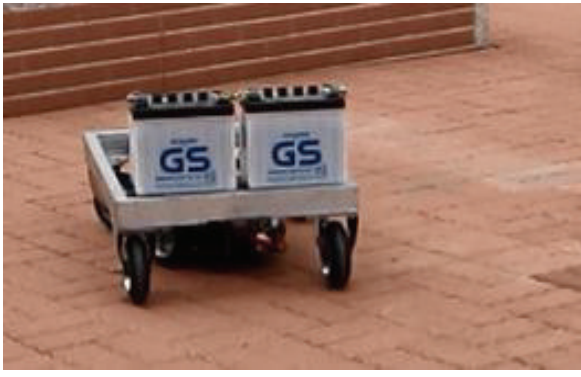

(i)

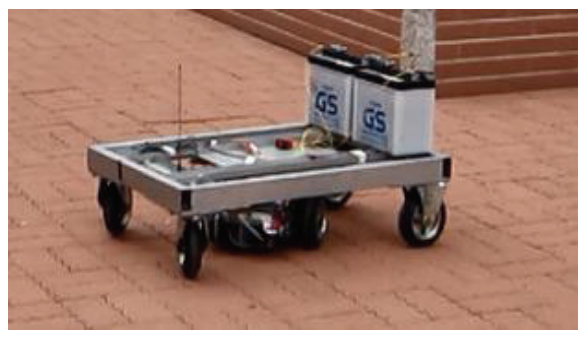

(l)

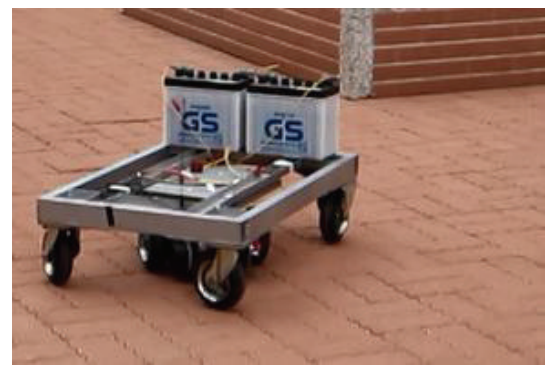

$(\mathrm{m})$

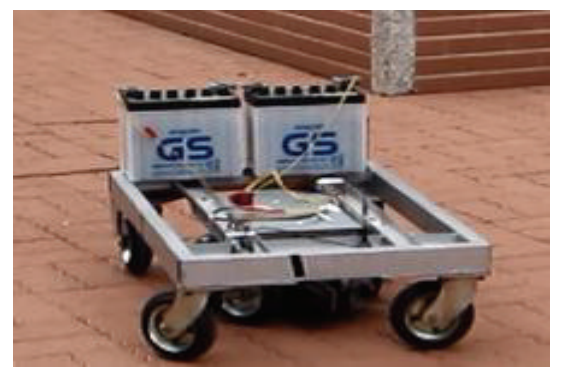

(n)

FIgUre 13: The taped videos to show the motion along the line and arc. 
2.3. Motion Control of AGV. On rotation of AGV with the center $O$, in Figure 4, point $Q$ stands for the center between left and right driving wheels, point $Q^{\prime}$ for the new position of $Q$ after vehicle traveling $\Delta t$ and $b$ for the half distance between two wheels, respectively. The distances of left wheel, right wheel, and $Q$ to $Q^{\prime}$ after vehicle traveling $\Delta t$ are denoted by $d_{l}, d_{r}$, and $d_{0}$, respectively, and can be expressed as follows [17]:

$$
\begin{gathered}
d_{l}=r_{l} \cdot \Delta \theta=V_{l} \cdot \Delta t, \\
d_{r}=r_{r} \cdot \Delta \theta=V_{r} \cdot \Delta t, \\
d_{0}=r \cdot \Delta \theta=V_{\mathrm{avg}} \cdot \Delta t,
\end{gathered}
$$

where $V_{l}$ and $V_{r}$ are the speeds of left and right driving wheels and $V_{\text {avg }}$ is their average value, $r_{l}, r_{r}$, and $r$ are the radii of the rotation along $O$, and $\Delta \theta$ is a rotating angle. As a result, we have the angular speed of the AGV and the displacements in $x$ and $y$ axes:

$$
\begin{gathered}
\omega=\frac{\Delta \theta}{\Delta t}=\frac{\left(V_{r}-V_{l}\right)}{2 b}, \\
\Delta x=r \cdot \cos (\Delta \theta)-r, \\
\Delta y=r \cdot \sin (\Delta \theta),
\end{gathered}
$$

where

$$
r=\left(V_{r}+V_{l}\right) \cdot \frac{b}{\left(V_{r}-V_{l}\right)}
$$

With the above information, we can direct the rotating motion of the AGV.

\section{Experimental Results}

The rated parameters of BLDC motor are power of $400 \mathrm{~W}$, input voltage of $24 \mathrm{~V}$, current of $16 \mathrm{~A}$, speed of $2500 \mathrm{rpm}$, torque of $1.53 \mathrm{Nm}$, and 8 poles. After training, the chosen topology is given to achieve good performance with minimal resources. After PID gain tuning [18] at speed of $300 \mathrm{rpm}$, we have the values for $K_{p}=0.1, K_{i}=0.01$, and $K_{d}=0.001$. Figure 5 displays speed responses of $300 \mathrm{rpm}$ at no load (blue curve) and the load of $500 \mathrm{~g}$ disc (red one). It is easy to find the accuracy by PID control and very small difference under loading. The step speed responses of $1200 \mathrm{rpm}$ are shown in Figure 6 with the same conditions in Figure 5. The speed difference of both cases increases. Figure 7 depicts those at $2000 \mathrm{rpm}$. The shortcoming of PID control is easily found. With RBFN adopted in the system, Figure 8 shows the speed response of $2000 \mathrm{rpm}$ at the load of $500 \mathrm{~g}$ disc, which is very approaching that of no load in Figure 7.

The pictures of the AGV prototype are shown in Figure 9, which consists of two BLCDM systems mentioned above, two batteries, and the third microcontroller for control center. The communication among these three microcontrollers is by CAN bus whose architecture is displayed in Figure 10. The block diagram of the AGV prototype is shown in Figure 11. Figure 12 displays the simultaneous speed responses of
$300 \mathrm{rpm}$ for left (red) and right (blue) wheels. We can find that the speed differences are small so that the vehicle is able to move along a straight line. Figures 13(a)-13(n) are the taped videos to show the motion along the line and arc. The experimental results have verified the designed AGV prototype with fundamental functions for real situations.

\section{Conclusions}

This paper presents an approach based on neural networks to compensate PID control gains for speed control of BLDCMs. The suggested method is useful for applications to reduce cost. The experimental results show that the controlled system is capable of achieving excellent speed response with loading and at full speed range within acceptable limits for many applications.

\section{Conflict of Interests}

The authors declare that there is no conflict of interests regarding the publication of this paper.

\section{Acknowledgments}

The authors would like to express their appreciation to Ministry of Science and Technology, Taiwan, and Eternity Electronic Industrial Company under contract no. MOST 103-2221-E-218-033- and 121030136 (Development of brushless servomotor drive systems) for financial supporting.

\section{References}

[1] A. Zaheer, G. A. Covic, and D. Kacprzak, "A bipolar pad in a 10$\mathrm{kHz} 300-\mathrm{W}$ distributed IPT system for AGV applications," IEEE Transactions on Industrial Electronics, vol. 61, no. 7, pp. 32883301, 2014.

[2] J. H. Cho and M.-W. Cho, "Effective position tracking using bspline surface equation based on wireless sensor networks and passive UHF-RFID," IEEE Transactions on Instrumentation and Measurement, vol. 62, no. 9, pp. 2456-2464, 2013.

[3] J. Villagra and D. Herrero-Pérez, "A comparison of control techniques for robust docking maneuvers of an AGV," IEEE Transactions on Control Systems Technology, vol. 20, no. 4, pp. 1116-1123, 2012.

[4] J. Perez-Ramirez, D. K. Borah, and D. G. Voelz, "Optimal 3$D$ landmark placement for vehicle localization using heterogeneous sensors," IEEE Transactions on Vehicular Technology, vol. 62, no. 7, pp. 2987-2999, 2013.

[5] K. Hameyer and R. J. M. Belmans, "Permanent magnet excited brushed DC motors," IEEE Transactions on Industrial Electronics, vol. 43, no. 2, pp. 247-255, 1996.

[6] J. Shao, D. Nolan, M. Teissier, and D. Swanson, "A novel microcontroller-based sensorless brushless DC (BLDC) motor drive for automotive fuel pumps," IEEE Transactions on Industry Applications, vol. 39, no. 6, pp. 1734-1740, 2003.

[7] T. Ohmae, T. Matsuda, K. Kamiyama, and M. Tachikawa, "A microprocessor-controlled high-accuracy wide-range speed regulator for motor drives," IEEE Transactions on Industrial Electronics, vol. 29, no. 3, pp. 207-211, 1982. 
[8] R. Wu and G. R. Slemon, "A permanent magnet motor drive without a shaft sensor," IEEE Transactions on Industry Applications, vol. 27, no. 5, pp. 1005-1011, 1991.

[9] S. Morimoto, M. Sanada, and Y. Takeda, "Sinusoidal current drive system of permanent magnet synchronous motor with low resolution position sensor," in Proceedings of the 31st IAS Annual Meeting, 1996 IEEE Industry Applications Conference, vol. 1, pp. 9-14, 1996.

[10] T. D. Batzel and K. Y. Lee, "An approach to sensorless operation of the permanent-magnet synchronous motor using diagonally recurrent neural networks," IEEE Transactions on Energy Conversion, vol. 18, no. 1, pp. 100-106, 2003.

[11] F. F. M. El-Fayez, "Hybrid Ho-based wavelet-neural-network tracking control for permanent-magnet synchronous motor servo drives," IEEE Transactions on Industrial Electronics, vol. 57, no. 9, pp. 3157-3166, 2010.

[12] H.-J. Guo, S. Sagawa, T. Watanabe, and O. Ichinokura, "Sensorless driving method of permanent-magnet synchronous motors based on neural networks," IEEE Transactions on Magnetics, vol. 39, no. 5, pp. 3247-3249, 2003.

[13] F.-J. Lin, L.-T. Teng, and H. Chu, "Modified Elman neural network controller with improved particle swarm optimisation for linear synchronous motor drive," IET Electric Power Applications, vol. 2, no. 3, pp. 201-214, 2008.

[14] H. Li, J. Wang, S. S. Gu, and T. Yang, "A neural-networkbased adaptive estimator of rotor position and speed for permanent magnet synchronous motor," in Proceedings of the 5th International Conference on Electrical Machines and Systems (ICEMS '01), vol. 2, pp. 735-738, Shenyang, China, April 2001.

[15] dsPIC33EP64MC506, 16-Bit Microcontrollers and Digital Signal Controllers Data Sheet, Microchip Technology, 2013.

[16] L. H. Tsoukalas and R. E. Uhrig, Fuzzy and Neural Approaches in Engineering, John Wiley \& Sons, 1997.

[17] Y.-S. He, Object following fuzzy control of the automatic guided vehicle [M.S. thesis], National Taipei University of Technology, 2005.

[18] G. Ellis, Control System Design Guide, Academic Press, San Diego, Calif, USA, 2nd edition, 2000. 


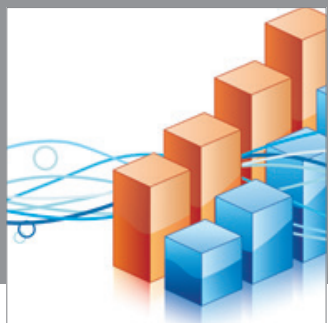

Advances in

Operations Research

mansans

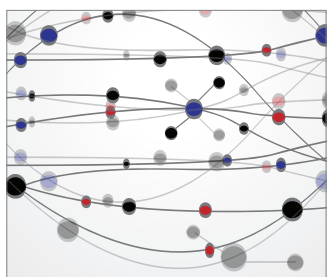

The Scientific World Journal
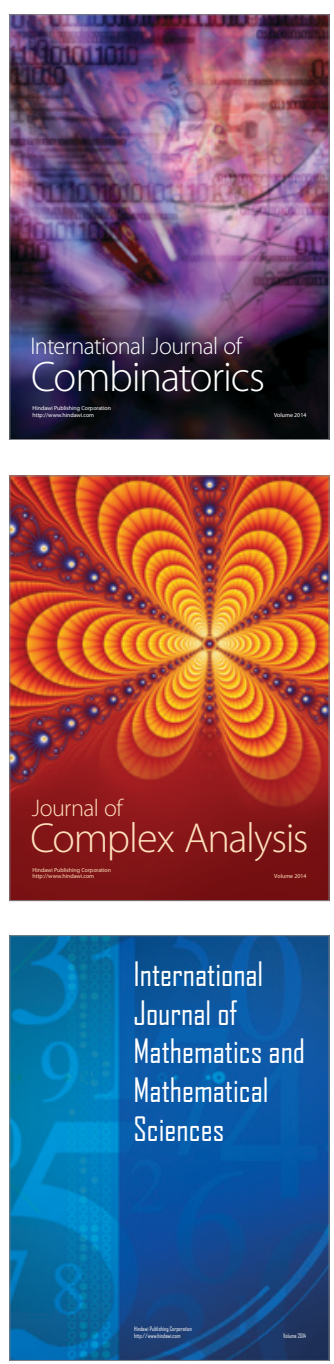
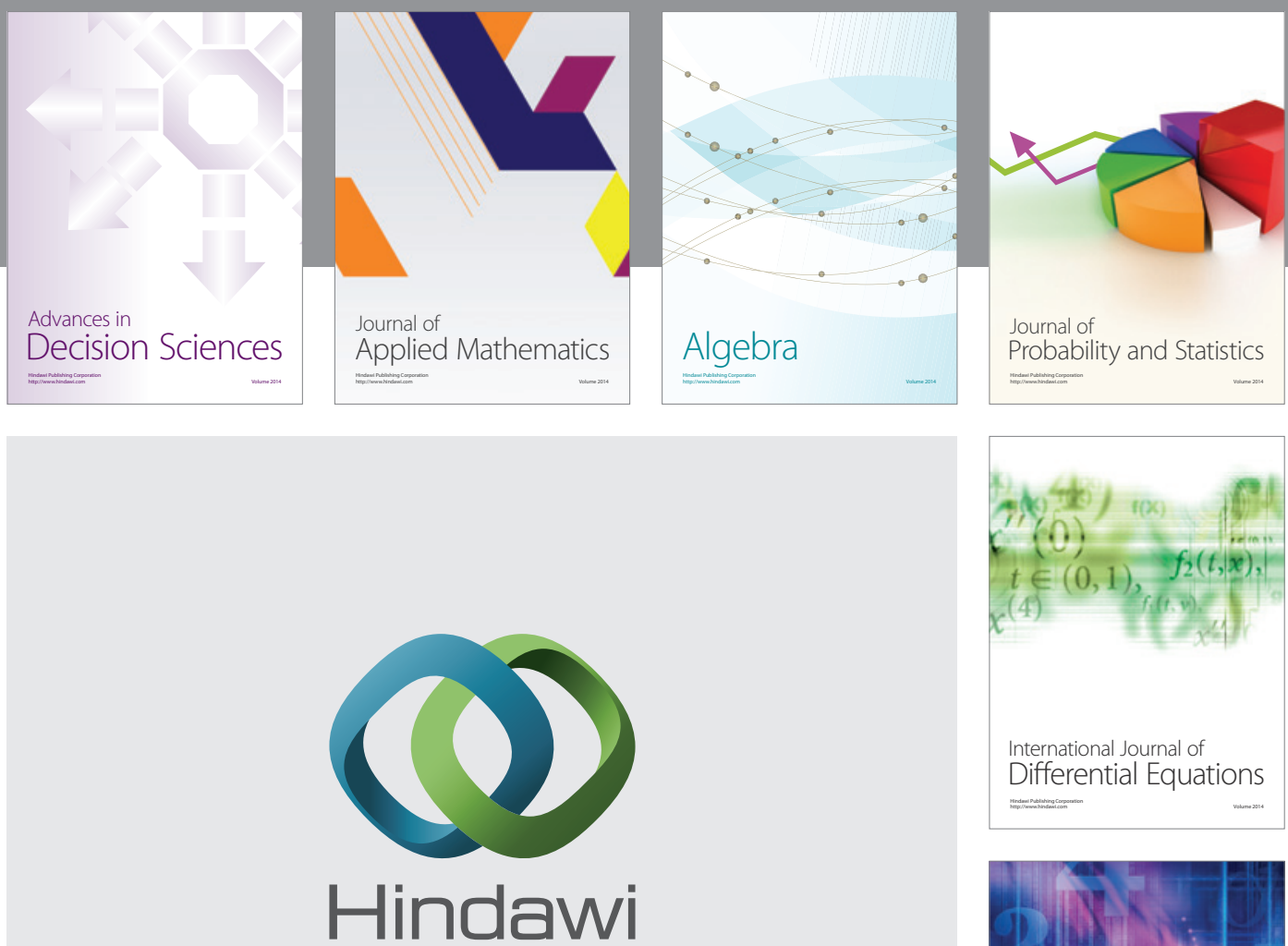

Submit your manuscripts at http://www.hindawi.com
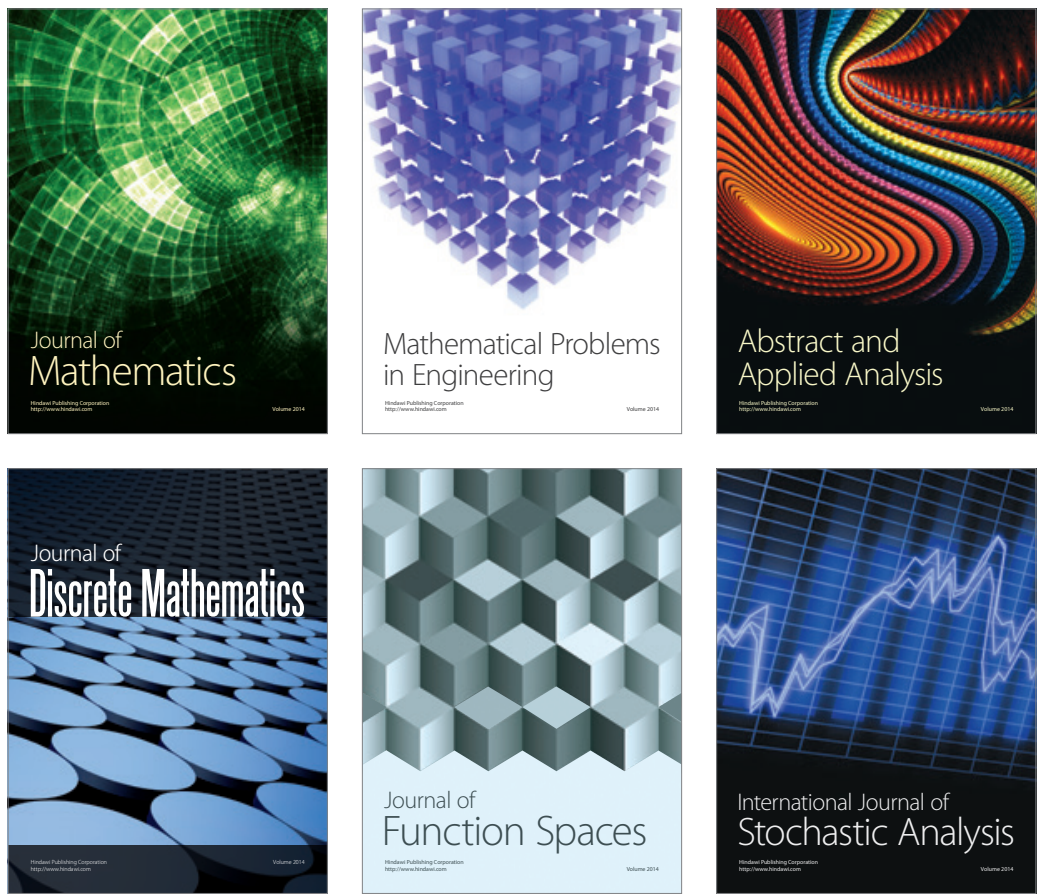

Journal of

Function Spaces

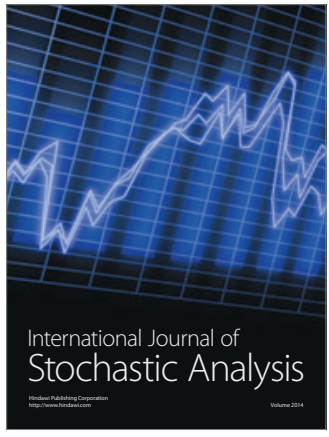

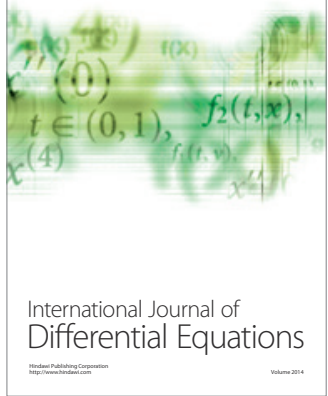
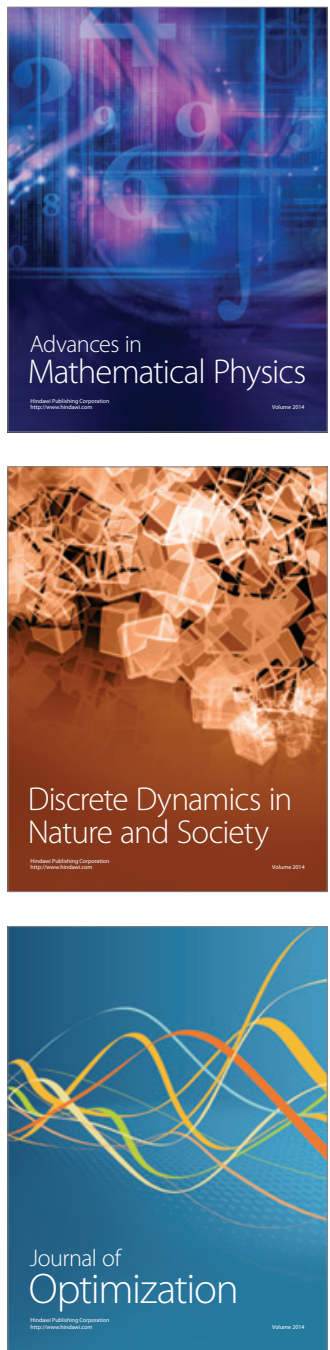